\title{
Effect of di-n-butylphthalate on the development of Spodoptera frugiperda
}

\author{
D. G. Montezano ${ }^{1}$, N. C. Vieceli ${ }^{2}$, E. M. Cardoso ${ }^{2}$, E. R. Lovatel ${ }^{2}$, \\ C. F. Gonzatti ${ }^{2}$, J. A. Marzotto ${ }^{2}$ \& I. N. Filho ${ }^{2,3}$ \\ ${ }^{I}$ Institute of Biotechnology, University of Caxais do Sul, RS-Brazil \\ ${ }^{2}$ Center of Exact Sciences and Technology, \\ University of Caxias do Sul, RS-Brazil \\ ${ }^{3}$ Institute of Environmental Sanitation, \\ University of Caxias do Sul, RS-Brazil
}

\begin{abstract}
The insect specie Spodoptera frugiperda is at the base of food sources for several bird species and contaminations detected in those insects can be transported to the birds as well as to the whole food chain. Di- $n$-butyl phthalate (DnBP) is a plasticizer added to polymers to facilitate processing and increase flexibility and toughness of the final product by internal modification of the polymer molecule. DnBP can interfere in the functioning of the endocrine system (endocrine disruptor) and in the mechanism of hormone action for several animal species. As plasticizers are used in packaging, clothing, films, paints, adhesives, cosmetics, ink printers and many other products, they are widespread in virtually all environments. The present study has investigated the bioaccumulation and influence of di- $n$-butyl phthalate (DnBP) on the physical development of Spodoptera frugiperda. A concentration of $1 \mathrm{mg} \mathrm{L}^{-1}$ of DnBP was added to the diet of two insect generations, in the larval phase. The insects in the adult phase were submitted to Soxhlet extraction with $n$-hexane and the organic extracts were analyzed by Gas Chromatography with Flame Ionization Detection (GC/FID). In the pupa phase the number of dead individuals was $17 \%$ higher, in relation to the control group. The reductions in weight and height of the individuals exposed to DnBP were 5.64 and $2.28 \%$ respectively, compared to the control group. In this way, we may conclude that at heavily contaminated sites, bird species that use Spodoptera frugiperda as a food source may be exposed to DnBP. The concentrations of DnBP in males and females of the second
\end{abstract}


generation were much higher than in the first one. However, death episodes of exposed individuals were ca. $57 \%$ minor in the second generation while reductions in size and weight were more pronounced.

Keywords: di-n-butylphthalate, soxhlet extraction, gas chromatography, endocrine disruptors, bioaccumulation.

\section{Introduction}

Plasticizers are organic esters added to polymers to facilitate processing and to increase the flexibility and toughness of the final product by internal modification of the polymer molecule. Some of these compounds are called phthalates and account for most polymer production.

DnBP (Figure 1) can interfere in the functioning of the endocrine system and in the hormonal mechanism. Endocrine deregulators or endocrine disruptors, such as DnBP, may cause reproductive anomalies (morphological and functional gonadal dysfunction, infertility and decreased libido), as well as congenital malformations [1-3]. Bornehag et al. [4] reported associations between dust concentrations of specific phthalate esters in house dust and asthma, rhinitis, and eczema in children. Phthalate esters were also detected in the serum of young Puerto Rican girls with premature breast development [5]. Long-term exposure to high concentrations of DnBP has shown to cause damage to the liver and testicles in mammals and death in aquatic species. DnBP can also influence the mobility and bioavailability of toxic substances, such as polychlorinated biphenyls and metal ions by changes in its water or lipid solubility [6].

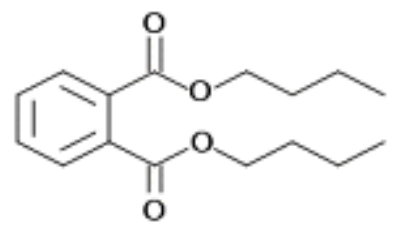

Figure 1: DnBP chemical structure.

As plasticizers are used in packaging, clothes, films, paints, adhesives, cosmetics, ink printers and many other products, it is widespread in virtually all environments. DnBP was also detected in mineral, ultra-pure and tap waters [7], municipal solid waste compost [8], sewage and wastewater treatment sludge [9] river sediments [6], landfill leachate $[10,11]$ and swine slaughterhouse wastewaters [12].

The Spodoptera frugiperda [13] belongs to the Insecta class and the Lepidoptera order. This specie was selected due to the easy development and possibility on individual bioassays. Those characteristics allow the evaluation of several parameters where the variations can be attributed as responses to chemical compounds. 
As Spodoptera frugiperda is at the base of food sources for several bird species, the main objectives of the present work were to evaluate the magnification and accumulation of DnBP on larva, pupa and adult individuals as well as death and physical modifications (as reduction in weight and length) promoted by DnBP.

The samples were extracted by Soxhlet and the instrumental analysis was performed by GC-FID.

\section{Methodology}

\subsection{Insects' maintenance and bioassays}

The insects' maintenance and bioassays were performed at $25 \pm 2{ }^{\circ} \mathrm{C}$ and relative humidity of $70 \pm 10 \%$ and $14 \mathrm{~h}$ of photo phase. The adults were maintained in cylindrical polyvinyl chloride (PVC) cages of $20 \times 20 \mathrm{~cm}$ (diameter $\mathrm{x}$ high). The mariposas were feed with honey aqueous solution $(10 \%)$. The eggs were transported to labeled petri plates until the larvae eclosion.

The bioassays were performed by following the development of 100 newborn larvae until the death in the adult phase. In the egg phase it was observed the fertility, considering at least 20 egg-laying from 5 couples that were feed with contaminated diet. The concentration of DnBP in the contaminated diet was 1 $\mathrm{mg} \mathrm{kg}{ }^{-1}$.

In the larva phase it was observed the number of instars, the duration of each stage, and the pre pupa period. The larvae survival was also observed. In the pupa phase the individuals were weighed and measured (long and laterally). In the adult phase it was evaluated the longevity considering the periods pre and post the eggs-laying.

\subsection{Samples' extraction}

The samples (approximately 1.457 and $1.537 \mathrm{~g}$ of the male female adults, respectively) were crashed in a mortar and extracted by Soxhlet by $4 \mathrm{~h}$ with $n$ hexane). The organic extracts were submitted to volume reduction (until $1 \mathrm{~mL}$ ) by a gentle flux of ultra-pure nitrogen.

\subsection{Instrumental analysis}

A PerkinElmer Gas Chromatograph model Autosystem XL, with Flame Ionization Detector was used for identification of DnBP by comparison between the retention times of the DnBP sample peak and the standard compound. The quantification was done by the internal normalization method. An Elite-5 fused silica capillary column (30 m x $0.25 \mathrm{~mm}$ i.d. crossbond 5\% diphenyl $-95 \%$ dimethyl polysiloxane, $0.25 \mu \mathrm{m}$ film thickness) was used for the GC separation using the following oven temperature program: $150^{\circ} \mathrm{C}$ ( 5 min hold $)$ heating to $250^{\circ} \mathrm{C}$ at $3^{\circ} \mathrm{C} / \mathrm{min}$ and heating to $300^{\circ} \mathrm{C}$ at $10^{\circ} \mathrm{C} / \mathrm{min}(5 \mathrm{~min}$ hold $)$. The injector temperature was $250^{\circ} \mathrm{C}$. The injection volume was $1.0 \mu \mathrm{L}(\mathrm{n}=3)$ in the split 
mode (1:50). During the entire experimental period, extraction blanks were analyzed by GC/FID and peaks of DnBP were not detected.

\subsection{Recovery grade and detection limit}

The recovery grades were measured by the extraction of real samples spiked with a DnBP standard solution $\left(20 \mathrm{mg} \mathrm{L}^{-1}\right)$. The detection limit was evaluated by successive dilutions of a DnBP standard solution $\left(100 \mathrm{mg} \mathrm{L}^{-1}\right)$.

\section{Results and discussion}

The detection limit was $0.5 \mathrm{mg} \mathrm{L}^{-1}$ and the detector response was linear between 1.0 and $50.0 \mathrm{mg} \mathrm{L}^{-1}\left(\mathrm{R}^{2}=0.931\right.$; equation: $\left.\mathrm{y}=8.908 \mathrm{x}-4.594\right)$. The recovery grade was $92 \%( \pm 1)$. The limit of quantification was $1.0 \mathrm{mg} \mathrm{L}^{-1}$.

\subsection{First generation}

According to Figure 2, the average concentration of DnBP in the female individuals was 5 times higher than in the male individuals.

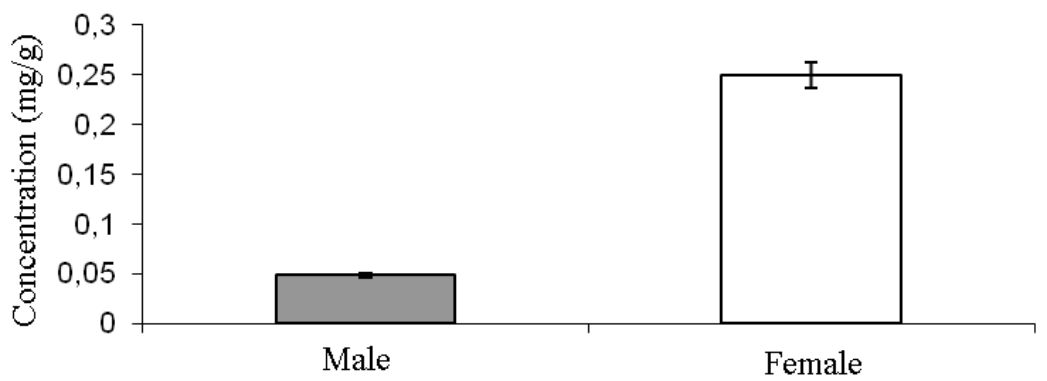

Figure 2: Average concentrations of DnBP in the male and female individuals. Error bars represent \pm standard deviations.

Some physical-chemical characteristics of DnBP like low water solubility $\left(0.013 \mathrm{mg} \mathrm{L}^{-1}\right)$ and $\log K_{\mathrm{OW}}$ (3.74) [14] can enhance the bio concentration of this compound. Wofford et al. [15] have reports plasticizers concentrations (including DnBP) in three aquatic species (Oyster Crassostrea virginica, Brown shrimp Panaeus aztcus and sheepshead minnow Cyprinodon variegatus). However, until we know, the present work is the first reporting measurements of DnBP in insect's species. Thus, published results cannot be compared.

Figure 3 show that the death effect on the individuals exposed to DnBP is not gender selective. 


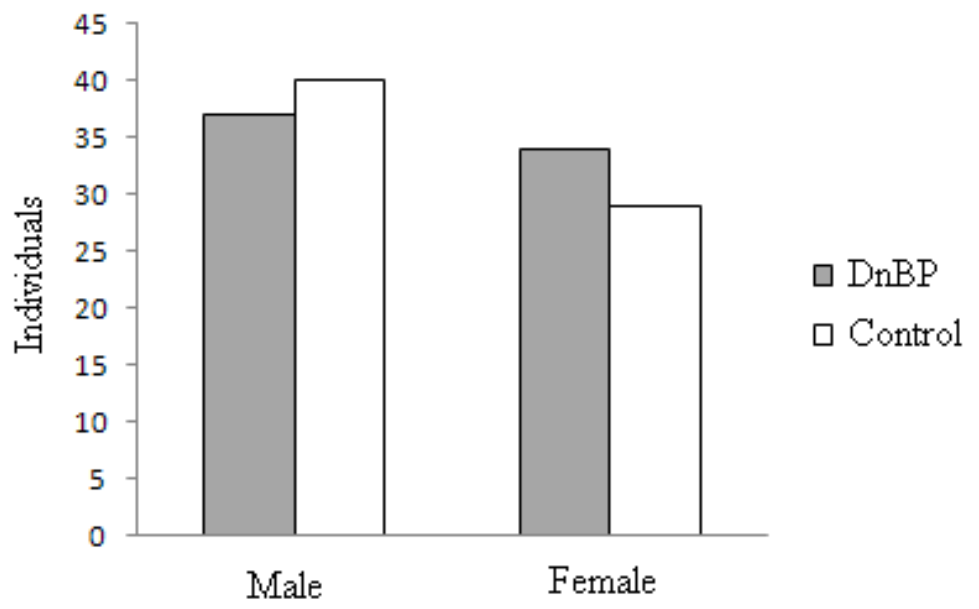

Figure 3: Death of male and female individuals exposed to DnBP.

In the pupa phase it was observed that the death of the individuals exposed to DnBP was $440 \%$ higher than in the control group (Figure 4). Probably this is the phase development where the organisms are more sensitive to xenobiotic compounds like DnBP.

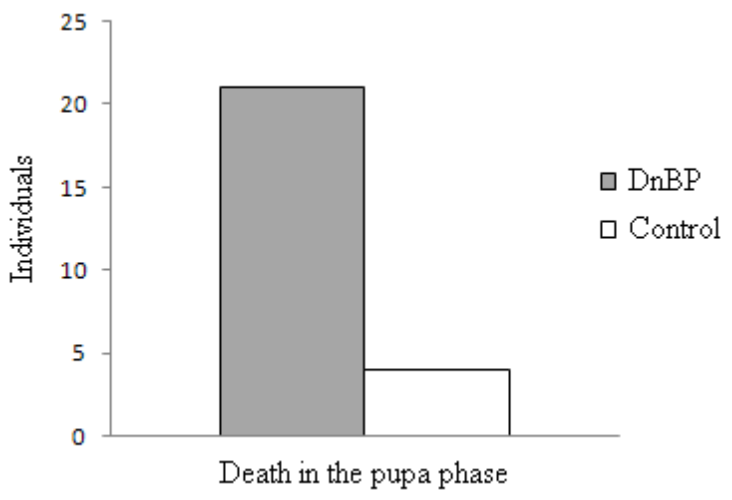

Figure 4: $\quad$ Death of the individuals exposed to DnBP in the pupa phase.

The individual's physical characteristics were also affected by the DnBP exposure. As can be seen in the Figures 5 and 6 size and weight of the individuals in the control group were 2.98 and $8.69 \%$ higher than the individuals exposed to DnBP. 


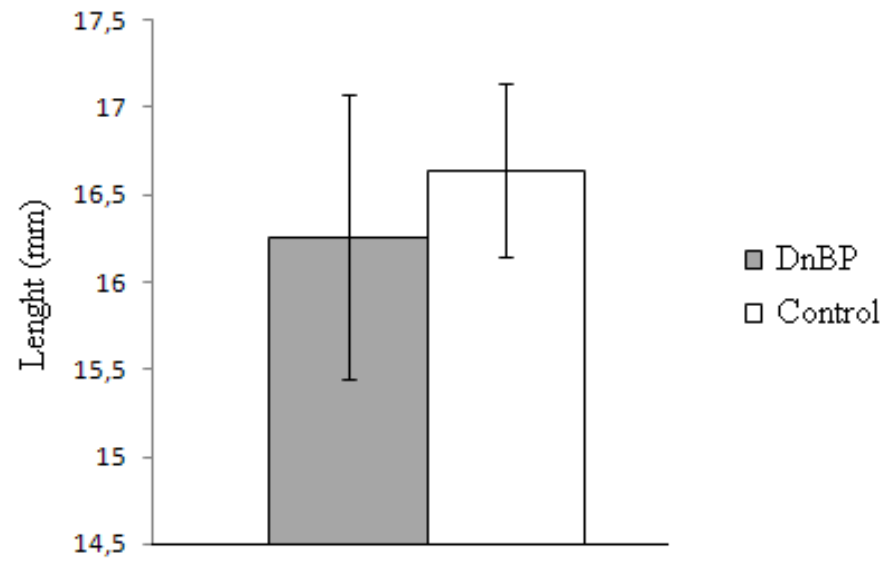

Effect on the individual's size

Figure 5: Average size of the individuals exposed to DnBP. Error bars represent \pm standard deviations.

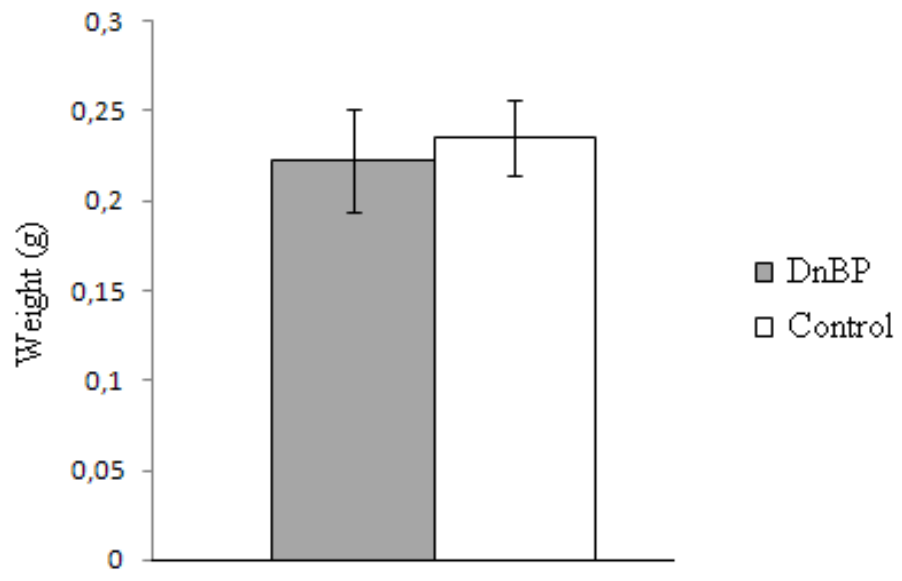

Figure 6: Average weight of the individuals exposed to DnBP. Error bars represent \pm standard deviations.

\subsection{Comparison between the first and second generations}

The concentrations of DnBP in males and females of the second generation were much higher than in first one (Figure 7). This means that DnBP is not only transferred from one generation to other but the concentrations increases by a factor of $970 \%$ (males) and $820 \%$ (females). 


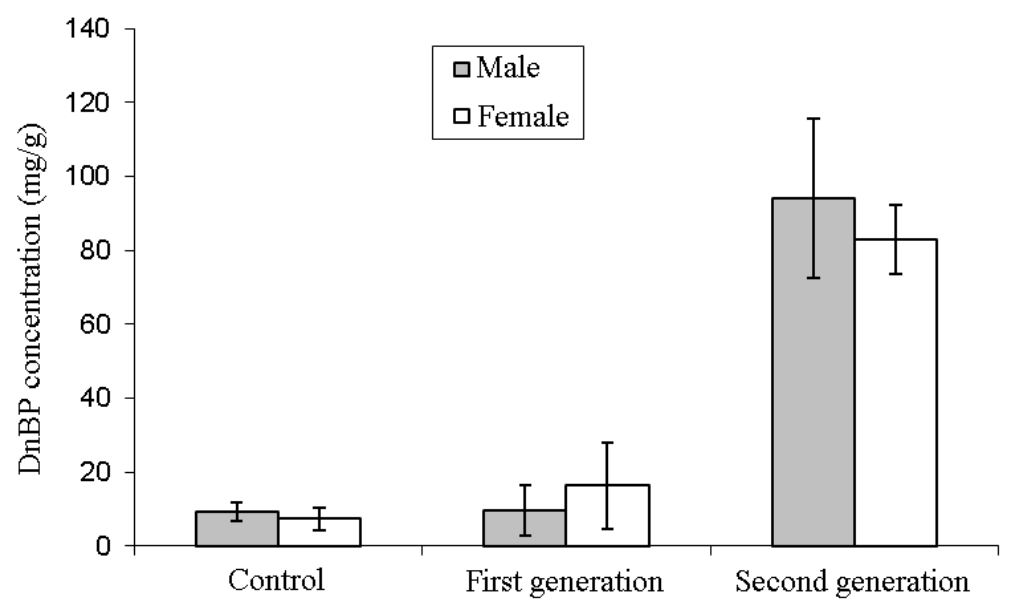

Figure 7: Average concentrations of DnBP of the exposed individual in the first and second generations. Error bars represent \pm standard deviations.

By other side, death episodes of the exposed individuals were ca. 57\% minor in the second generation (Figure 8). This result suggests some kind of metabolic adaptation or resistance development of the second generation individuals in relation to DnBP.

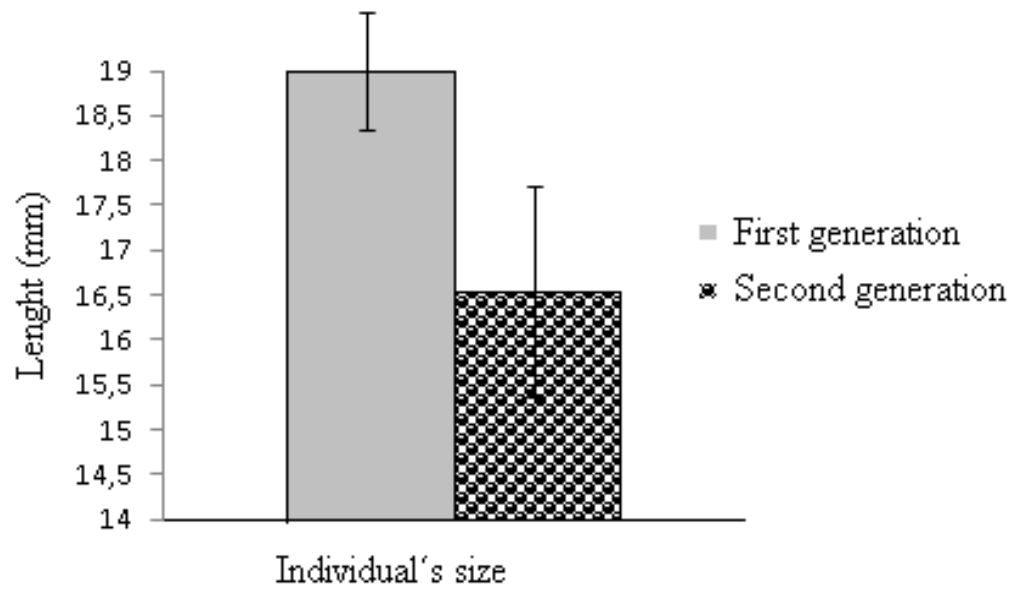

Figure 8: Average size of the individual's exposed to DnBP in the first and second generations. Error bars represent \pm standard deviations.

The reductions of the individual's size and weight were more pronounced in the second generation (Figure 9). 


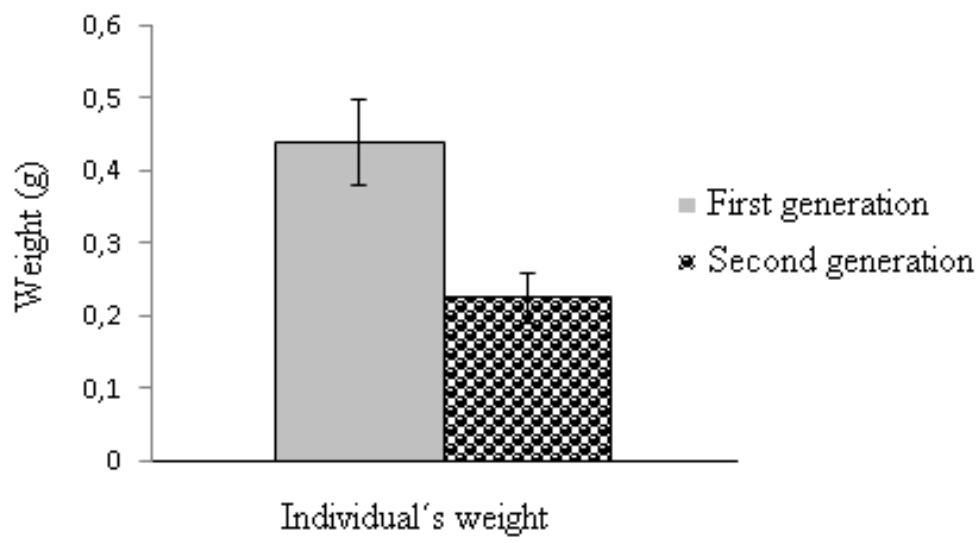

Figure 9: Average weight of the individual's exposed to DnBP in the first and second generations. Error bars represent \pm standard deviations.

\section{Conclusions}

In the present work it was observed that DnBP has a negative effect over the development of Spodoptera fruguperda. The death of the individuals exposed to DnBP was $440 \%$ higher than in the control group. The size and weight of the individuals in the control group were 2.98 and $8.69 \%$ higher than the individuals exposed to DnBP. In this way, we can conclude that a serious contamination at these insects habitat can drastically compromise the health of the birds that use these insects as food source. In the same way, these birds can be exposed to high concentrations of DnBP.

The reduction of average size and weight of the second generation of individuals exposed to DnBP may lead to a less abundant food source, bird migration and a serious breakdown for an entire ecosystem.

The next steps of our work will be on how much concentration of DnBP can be transferred to the upper stages of the food chain, starting from the insect's contamination.

\section{Acknowledgements}

The authors thank CNPq, the University of Caxias do Sul and the technicians of the IB-UCS.

\section{References}

[1] Nelson, P., Epidemiology, biology, and endocrine disrupters. Occupational Environmental Medicine, 60, pp. 541-542, 2003.

[2] Mantovani, A., Problems in testing and risk assessment of endocrine disrupting chemicals with regard to developmental toxicology. Chemosphere, 39, pp. 1293-1300, 1999. 
[3] Gray, J.R., Prostate cancer risk groups and comparisons: fruitless or fruitful? Journal of Clinical Oncology, 20, pp. 4129-4130, 2002.

[4] Bornehag, C., Sundell, J., Weschler, C. J., Sigsgaard, T., Lundgren, B., Hasselgren, M. and Hägerhed-Engman, L., The association between asthma and allergic symptoms in children and phthalates in house dust: a nested case-control study. Environmental Health Perspective, 112, pp. 1393-1397, 2004.

[5] Colón, I., Caro, D., Bourdony, C.J. and Rosario O., Identification of phthalate esters in the serum of young Puerto Rican girls with premature breast development. Environ. Environmental Health Perspective, 108, pp. 895-900, 2000.

[6] Möder, M., Popp, P. and Pawliszyn, J., Characterization of water-soluble components of slurries using solid-phase microextraction coupled to liquid chromatography-mass spectrometry. Journal of Microcolumn Separations, 10, pp. 225-234, 1998.

[7] Bauer, M.J. and Herrmann, R., Estimation of the environmental contamination by phthalic acid esters leaching from household wastes. Science of the Toal Environment, 208, pp. 49-57, 1997.

[8] Akon, H., Yoon B., Takayuki, K., Mariko, H., Maya, M. and Takashi, N., Separation of endocrine disruptors from aqueous solutions by pervaporation: DEHP and butylated hydroxytoluene in mineral water. Journal of Applied Polymer Science, 94, pp. 1737-1742, 2004.

[9] Gonzalez-Vila, F.J., Saiz-Jimenez, C. and Martin F., Identification of free organic-chemicals found in composted municipal refuse. Journal of Environmental Quality, 11, pp. 251-254, 1982.

[10] Boyd, S.A., Sommers, L.E. and Nelson, D.W. Infrared spectra of sewage sludge fractions-evidence for an amidemetal-binding site. Journal of the American Soil Science Society, 43, pp. 893-899, 1979.

[11] Nascimento, I.F., von Muhlen, C., Schossler, P. and Caramão, E.B. Identification of some plasticizers compounds in landfill leachate. Chemosphere, 50, pp. 657-663, 2003.

[12] Aguilar, C.P., Peruzzolo, M., Di Luccio, M., Dallago, R.M. and Nascimento, I.F. Qualitative study of organic compounds in wastewaters of a swine slaughterhouse. Environmental Monitoring and Assessment, 116, pp. 103-110, 2006.

[13] Rodrigues, S.R., Coutinho, G. V., Garcez, W.S., Garcez, F. R. and Zanella, D.P.F. Atividade inseticida de extratos etanólicos de plantas sobre Spodoptera frugiperda (J.E.Smith) (Leptopdera: Noctuidae). Agrarian, 1, pp. 133-144, 2008.

[14] Cousins, I.T., Mackay, D. and Parkerton, T.F., Physical-chemical properties and evaluative fate modelling of phthalate esters. In The handbook of environmental chemistry; Charles, A.S., ed.; Springer: New York, 2003.

[15] Wofford, H.W., Wisley, C.D., Neff, G.S. and Giam, C.S., Bioaccumulation and metabolism of phthalate esters by oysters, brown shrimp, and sheepshead minnows. Ecotoxicology and Environmental Safety, 5, pp. 202$210,1981$. 